\title{
Application of phase change material in thermal energy storage system: A Review
}

\author{
S.B.Gawas \\ Asst. Professor, Department of Mechanical Engineering \\ SSPMCOE Kankavli, Maharashtra, India \\ Aishwarya A.Asolkar \\ UG student, Department of Mechanical Engineering \\ SSPMCOE Kankavli, Maharashtra, India \\ Shraddha A. Mane \\ UG student, Department of Mechanical Engineering \\ SSPMCOE Kankavli, Maharashtra, India
}

\begin{abstract}
While changing the phase of substance from solid to liquid or liquid to solid, heat energy is store or loss in the form of latent heat. This latent heat of the substance can be utilize in many applications by storing in thermal energy storage system (TES). This review article focuses the scope of phase change material (PCM) in application and enhancement of thermal energy storage (TES) system. It is a new approach to utilize renewable energy into useful work by using phase change material. Encapsulation, microencapsulation, etc; are the methods that uses to implement PCM in thermal energy storage system to enhance the capacity and stability of storage system. Phase change material can be solidifies and melt at room temperature so that it is widely used in building sector for cooling and heating purpose.
\end{abstract}

Keywords — Thermal energy storage, Phase change material, latent heat, encapsulation, renewable energy.

\section{INTRODUCTION}

The utilization of renewable energy is obvious catches the attention of many researchers and scholars now a day due to its availability. The Solar Energy is one of the well-known forms of the renewable energy which can be used for different application by developing and designing new systems. Existing solar energy devices are solar water heater, solar air heater, solar collector, etc; where energy of solar radiation is collected and converts into useful work. Researches and experimental study is continuously going on to enhance the utilization of solar energy, one of the new trends that emerging in this field is Thermal Energy Storage (TES) System using Phase Change Material (PCM). Phase change material stores and loses the energy in the form of latent heat during changing the phase from solid to liquid or vice-versa. PCM can solidifies and melt at room temperature also and due to this property it is extensively used as thermal energy storage system in many application like building sector for cooling and heating, solar water heater, air heater, convective cooling system etc.

The heat is supply to the substance in two form i.e.; sensible heat and latent heat. If temperature of the substance is changes on addition or removal of heat it is known as sensible heat, where application of heat, changes the phase of the substance, is called latent heat. Latent heat is stored in the substance at constant temperature during phase change.

The working mechanism of phase change material (water at $1 \mathrm{~atm}$ pressure) is elaborated as follows. 


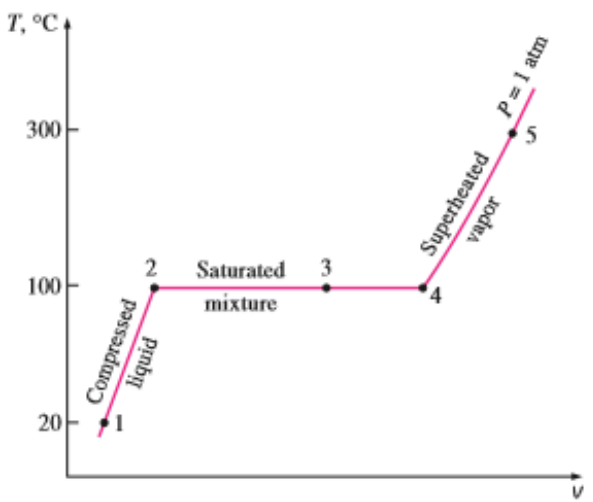

Figure 1: Phase change mechanism of water[1]

If we supply heat energy to the ice which is below $0^{\circ} \mathrm{C}$ (say $-5^{\circ} \mathrm{C}$ ) and 1 atmospheric pressure, temperature will increases $\left(\right.$ say $0^{\circ} \mathrm{C}$ ). During this rise in temperature thermal energy is stored in the form of sensible heat. Further addition of heat convert the ice $\left(0^{\circ} \mathrm{C}\right)$ into water at $0^{\circ} \mathrm{C}$. Here the phase changes occur from ice to liquid but temperature remains constant i.e. $0^{\circ} \mathrm{C}$. Once all the volume of ice is converted in water further addition of heat increases the temperature of water up to $100^{\circ} \mathrm{C}$. At $100^{\circ} \mathrm{C}$ water is converted into steam on addition of heat. While changing the phase of water, latent heat is stored as a thermal energy.

On the basis of various experimental studies and researches, it has been proved that latent heat of phase change material can be utilize for different application. The present review is based on thermal energy storage systems, methods to enhance its capacity and its application.

\section{EUTECTIC ALLOY AS PCM}

E. Risueno. A. Faik et.al. [2]; investigated two high thermal conductive ternary eutectic alloys $\mathrm{Mg}_{70} \mathrm{Zn}_{24.9} \mathrm{Al}_{51}$ and $\mathrm{Mg}_{6} \mathrm{Zn}_{85.5} \mathrm{Al}_{8.2}$ with theoretical melting points of $611 \mathrm{~K}$ and $618 \mathrm{~K}$ respectively for latent heat storage in concentrate solar power (CSP) applications, also studied the thermal stability to analyze the thermal performance after 700 cycles. Pre-alloys of this materials with a weight of $60 \mathrm{~g}$ were prepared in stoichiometric proportions. The pre-alloys then hermetically closed inside the stainless steel reactors, this reactor were placed in an electrical muffle furnace and maintained at $723 \mathrm{~K}$ for 10 hours. Cooling process were carried out at a rate of $10 \mathrm{~K} / \mathrm{min}$. By inductively coupled plasma spectrometry, the homogeneity of materials was confirmed

X-ray powder diffraction (XRPD), scanning electron microscopy (SEM) and energy dispersive X-ray spectrometry (EDX) techniques were used for structural characterization.

The thermal stability test was performed between 553 and $673 \mathrm{~K}$ by means of short and long term experiments with heating/cooling rates of $10 \mathrm{~K} / \mathrm{min}$ and under argon atmosphere.

The fig (a) and (b) shows the result for 100 cycles and 700 cycles performed by DSC technique for $\mathrm{Mg}_{70} \mathrm{Zn}_{24.9} \mathrm{Al}_{5.1}$.

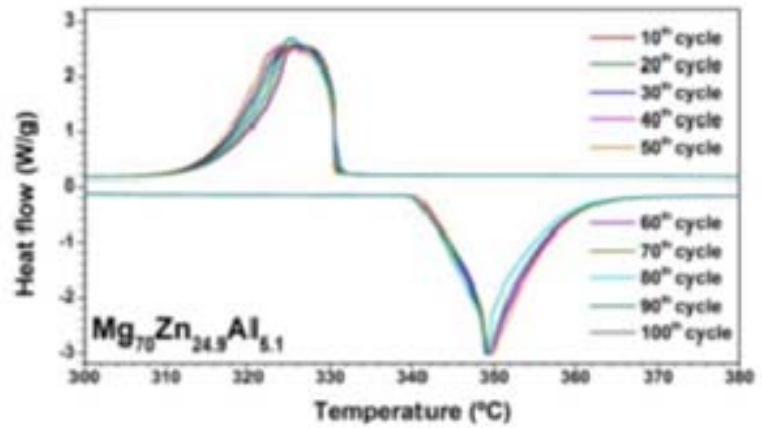

Figure 2: Thermal stability for 100 cycles 


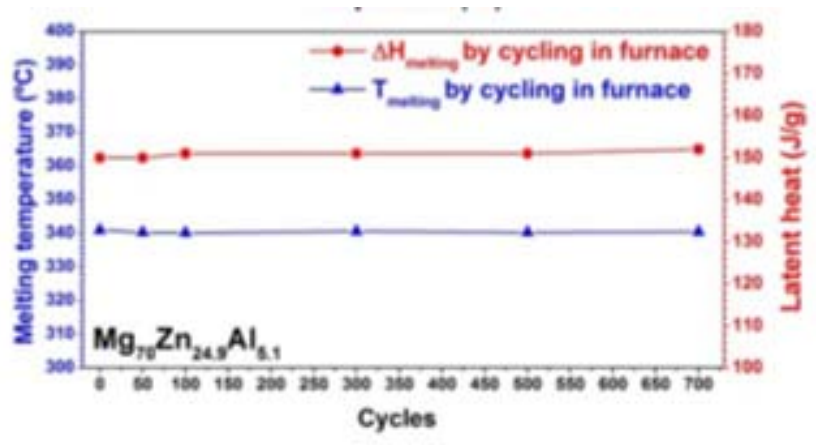

Figure 3: Thermal stability for 700 cycles

The result shows that a good thermal stability was observed for at least 100 cycles for $\mathrm{Zn}_{85.5} \mathrm{Al}_{8.2} \mathrm{Mg}_{6}$ eutectic alloys and at least 700 cycles for the $\mathrm{Mg}_{70} \mathrm{Zn}_{24.9} \mathrm{Al}_{5.1}$ eutectic alloy.

\section{HS-58 AS PCM FOR ENHANCEMENT OF TES}

Apart from the use of PCM in thermal energy storage, many experimentation works have done to enhance the storage capacity. S. A. Khot [3] principal of S.I.T. college of Engineering, Maharashtra, investigated HS-58 phase change material with melting point $56.9^{\circ} \mathrm{C}$ to increase thermal energy storage through experimentation. In this article Author compare the results of PCM-water pair with water only in domestic solar water heating application. The experimental set up consists of thermal storage tank, solar collector simulation unit, water reservoir, spherical capsule filled with HS-58 as shown in fig.4

PCM were used in capsule made by high density polyethylene which contains $184 \mathrm{~g}$ of HS-58 per capsule. Total 12 capsules were used. $16 \mathrm{~K}$-type thermocouples were inserted along with data acquisition unit to record readings.

Two different experimental conditions were designed for same heat input and reading were recorded for PCMwater combination and water only. Experimental work proved that improvement in thermal storage system by $22 \%$ using PCM- water combination than water only. The element comprises of $75 \mathrm{~mm}$ outer diameter spherical capsule made up of high density polyethylene (HDPE) material having a wall thickness of $1.5 \mathrm{~mm}$ and field with HS-58 PCM.

Fig. 5 shows relation between temperature and time of PCM in first graph and water in second graph for same heat input that says use of PCM-water pair enhanced thermal storage.

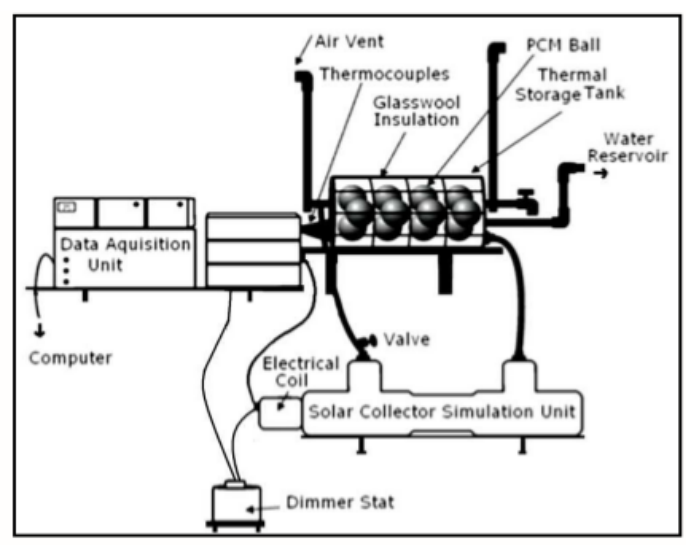

Figure 4: Experimental set up by S.A.Khot 

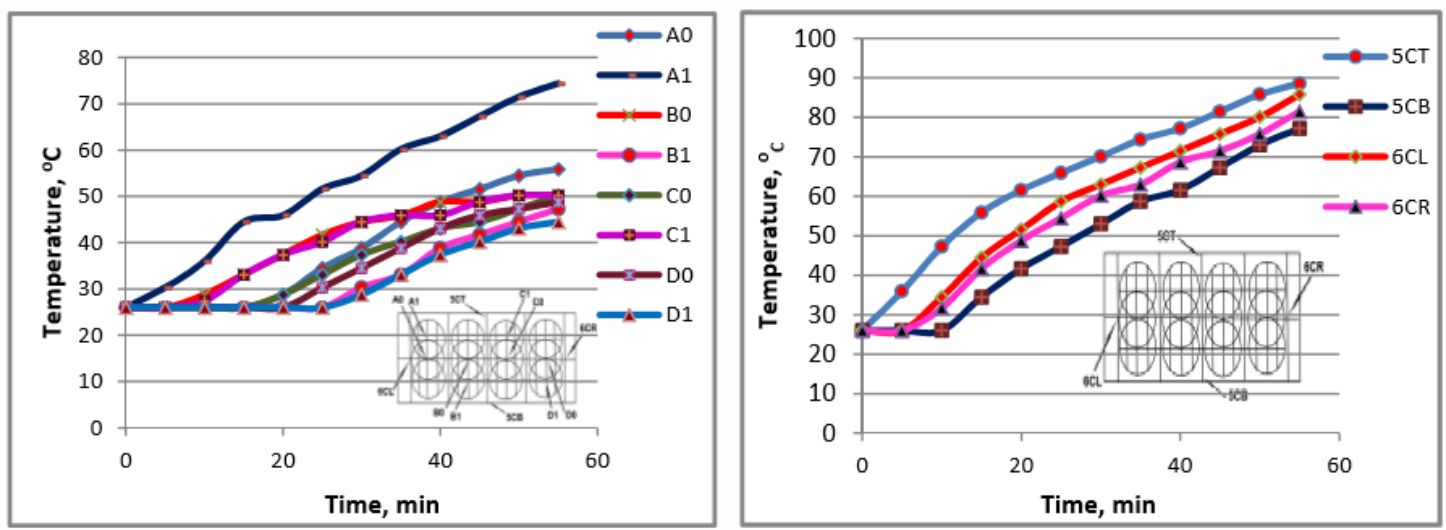

Figure 5: During controlled energy input, temp- time variation of PCM and water

\section{PCM BASED THERMAL ENERGY STORAGE}

M.J. Kabbara, et.al [4] experimentally investigated performance of thermal energy storage system based on encapsulated PCM in cylinders. Experimental set up consist 49 PVC tubes which equally distributed $121.30 \mathrm{~kg}$ of calcium chloride hydrate with freezing point $27-28^{\circ} \mathrm{C}$ and latent heat of fusion $170 \mathrm{kj} / \mathrm{kg}$.

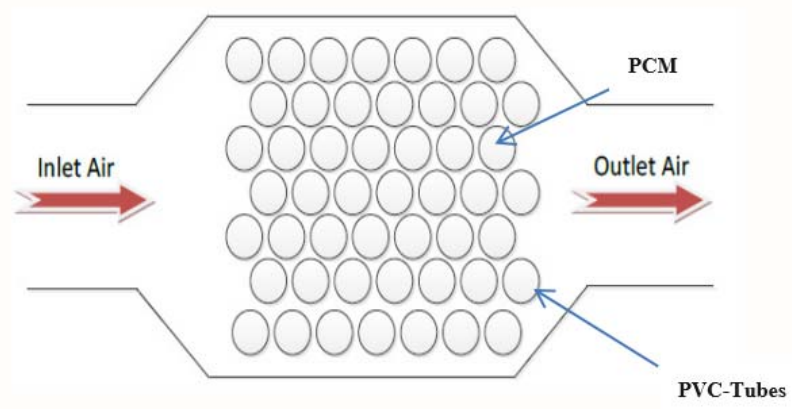

Figure 6: layout of TES unit

To analyze temperature profiles for melting and freezing processes three flow rates were tested i.e. $0.102 \mathrm{~kg} / \mathrm{s}, 0.182$ $\mathrm{kg} / \mathrm{s}, 0.235 \mathrm{~kg} / \mathrm{s}$. The equation $\mathrm{Q}_{\text {inst }}=\mathrm{m} \mathrm{Cp} \Delta \mathrm{T}_{\text {air }}$ used for calculating instantaneous heat transfer rate. The results were favorable to use PCM based thermal energy storage unit but not all the material inside the tubes was melt and this can become a part of future investigation.

\section{PCM IN BUILDING APPLICATION}

The use of phase change material is possible in building sector for cooling and heating purpose and this study is done by Alvaro de Gracia et.al. [5]. Author explored the application area of TES system in building sector as Active and Passive Technologies. Passive systems can enhance the naturally available heat energy sources in order to maintain the comfort conditions in buildings and minimize the use of mechanically assisted heating or cooling systems like ventilated facades, thermal mass, solar heating and free cooling techniques. Where active TES systems provide a high degree of control of the indoor conditions and improve the way of storing heat energy using HVAC systems.

PCM can be integrated in construction materials using different methods, such as direct use, immersion, encapsulation, microencapsulation and shape-stabilization. Traditionally, wallboards have been studied as one of the best options to incorporate PCM to building walls. A new approach in PCM-wallboards is the addition of the PCM supported by expanded graphite nanosheets to improve its thermal conductivity with the aim enhanced thermal storage and energy distribution. The same objective was pursued with the addition of an aluminium honeycomb in a containing microencapsulated PCM wallboard.

\section{PCM WITH HEAT PIPES AND FINS}


In solar power station high temperature heat source is required as input to the turbine for power generation but it is time dependent. To get rid of this issue D.J.Malan et.al [6] have designed modular phase change storage system using heat pipes and metallic fins so that sufficient amount of heat stored in PCS system to enhance heat transfer rate. This design have been used as building block in PCS system for solar power generation. The developed module for this experiment comprises heat pipes and rectangular fins with $0.87 \mathrm{~kg}$ paraffin wax inserted into it having melting point $59^{\circ} \mathrm{C}$. To transfer heat energy even across a small temperature range heat pipes were selected on basis of boiling of the fluid at the lower evaporator section and condensation of the vapor at the higher condenser section.

By using the developed working module author have performed day wise operations and described melting and solidification process of a phase change material in that particular geometry.

\section{OTHER APPLICATIONS}

Solar radiation is a huge source of heat energy and lot of researches have been made and also going on to utilize this energy for different application areas. Even after its great scope and free cost availability, solar energy is not extensively used due to storage problem. Phase change material is a new way to store the heat energy and transfer for desired applications. Many authors experimentally proved the storage of heat energy by using different phase change materials.

Vinod yadav et.al [] applied the phase change material i.e. $\operatorname{savE}^{\mathrm{R}} \mathrm{HS} 29$ in motorcycle helmet for cooling purpose.

The paraffin wax with melting point of $54^{\circ} \mathrm{C}$ [7] can be used in solar water heater system to get hot water in the morning.

Encapsulated phase change material like paraffin wax, fatty acids, butyl stearate can be used in floor, ceiling and walls for cooling / heating of building. [8]

Use of phase change in green houses to store and utilize solar energy for curing, drying process or plant production is becoming more popular. [8]

Apart from the application area of phase change material in thermal energy storage system, there are some disadvantages like corrosion, low thermal conductivity, storage etc; we need to overcome through future study.

\section{CONCLUSION}

Use of renewable energy is a todays need as this energy has enormous availability at free of cost. Phase change material for storing the heat energy is emerging technique. After studying the many research papers we can conclude that, phase change material is effective material to store thermal energy even for small temperature range. Maximum utilization of solar radiation is possible by carefully studying some parameters like melting and solidification point of material, methods to use PCM, thermal conductivity, corrosion and desired type of application.

\section{REFERENCES}

[1] Cengel, Boles, "Thermodynamics An engineering approach" fifth adition page no 115.

[2] E. Risueñoa, A.Faika, J. Rodríguez-Aseguinolazaa, P. Blanco-Rodrígueza, A.Gila, M. Tellob and B. D’Aguannoa, "Mg-Zn-Al eutectic alloys as phase change material for latent heat thermal energy storage", International Conference on Concentrating Solar Power and Chemical Energy Systems, SolarPACES 2014, pp 1006-1013.

[3] S.A.Khot, "Enhancement of Thermal Storage System using Phase Change Material", 4th International conference on advances in Energy Reasearch 2013, pp 142-151.

[4] M.J. Kabbaraa, N.Ben Abdallaha, "Experimental investigation on phase change material based thermal energy storage unit", The 3rd International Conference on Sustainable Energy Information Technology, pp 694-701, 2013

[5] Alvaro de Gracia, Luisa F. Cabeza, "Phase change materials and thermal energy storage for buildings", Energy and buildings, pp 414-419, 2015.

[6] D.J. Malan, R.T. Dobson, F. Dinter, "Solar thermal energy storage in power generation using phase change material with heat pipes and fins to enhance heat transfer", International Conference on Concentrating Solar Power and Chemical Energy Systems, SolarPACES 2014, pp 925-936.

[7] Vinod Yadav, Awadhesh Kumar Yadav, Nishant Kumar Srivastava, Pravesh Kumar Srivastava, Suresh Kumar Gigoo, "Experimental Analysis of the Cooling of a Motorcycle Helmet by Using Phase Change Material with Forced Convection", International Journal of Science and Research (IJSR), ISSN (Online): 2319-7064, Volume 6 Issue 1, January 2017.

[8] Prof Anup M. Gawande, Mr. Atul P. Wasolkar, “ Thermal Energy Storage by Phase Change Material”, International Research Journal of Engineering \& Technology, volume: 3, issue: 10, 2016. 